\title{
AC 2011-485: IMPLEMENTATION OF A BIOMEDICAL ENGINEERING SUMMER PROGRAM FOR HIGH SCHOOL STUDENTS
}

Judy L. Cezeaux, Western New England College

Michael J Rust, Western New England College

Robert Gettens, Western New England College

Richard D. Beach, Western New England College

Dr. Richard D. Beach earned his PhD in Biomedical Engineering from the University of Connecticut in 2000, Dr. Beach also has an MS Computer Science from Rensselaer Polytechnic Institute, Troy, NY and BS Electrical Engineering from Fairfield University, Fairfield, Connecticut.

Prior to his faculty position as Visiting Assistant Professor of Biomedical Engineering at Western New England College, Dr. Beach was an Adjunct Assistant Professor of Biomedical Engineering and Research Associate at Worcester Polytechnic Institute. Before this he was a Research Instructor and Postdoctoral Fellow at the University of Massachusetts Medical School in the Radiology Department, Division of Nuclear Medicine, in the Medical Physics Group. Earlier Research Instructor and Postdoctoral Fellow work was also done at the University of Connecticut, Storrs, CT and University of Connecticut Health Center in Farmington, CT.respectively.

Jason A Criscuolo, Western New England College 


\title{
Implementation of a Biomedical Engineering Summer Program for High School Students
}

\begin{abstract}
The biomedical engineering program at Western New England College recently hosted a oneweek residential summer program for high school students. Students participated in laboratory experiences involving biomaterials, lab-on-a-chip, bioinstrumentation, microscopy, sports biomechanics, robotic surgery, engineering design, cell and tissue engineering, neural engineering, and physiological response to acceleration. Assessment of the program was performed using pre- and post-program surveys with both quantitative and qualitative questions. Results of the surveys indicate that the program was successful in introducing participants to the field of biomedical engineering, career opportunities for biomedical engineering graduates, and the educational opportunities available in biomedical engineering at the host institution.
\end{abstract}

Introduction

Summer engineering outreach programs are used as a recruitment tool for potential students as well as to introduce students to the various engineering fields. Many engineering schools across the country offer either residential or day programs that provide junior high or high school students the opportunity to investigate engineering as a college major and career choice. These programs generally expose students to multiple engineering fields during the program.

Although engineering summer programs are ubiquitous, those concentrating entirely on bioengineering or biomedical engineering are scarce. An internet search revealed a handful of summer programs whose primary focus is on bioengineering. Milwaukee School of Engineering hosts a residential program for rising high school sophomores, juniors, and seniors entitled "Focus on the Possibilities: Biomedical Engineering" which concentrates significantly on biosignals and their measurement. ${ }^{1}$ The University of Washington has previously hosted a bioengineering day program focusing on computational bioengineering, home health care, engineered biomaterials, medical imaging, and nanotechnology for rising $9^{\text {th }}$ and $10^{\text {th }}$ graders. ${ }^{2}$ In the summers of 2008 and 2009, Wichita State University held a day program entitled "Body Works: The Body as a Machine" that introduced high school students to medical devices, lifestyle engineering and bioenergy. ${ }^{3,4}$ Participants for both of these day programs were limited to students in the local area who could commute to the program each day. The University of Illinois at Urbana-Champaign, on the other hand, runs the residential Girls Adventures in Mathematics, Engineering, and Science (G.A.M.E.S.) Camp for rising $9^{\text {th }}$ and $10^{\text {th }}$ grade girls where participants may choose to focus on bioengineering \& chemical engineering. 5 This program, however, is not solely focused on bioengineering and its participants are limited to girls only. Thus, to our knowledge, there are few programs available for a wide audience of high school students who want to further explore their interests in bioengineering or biomedical engineering.

In an effort to expose high school students from across the country to the diverse field of biomedical engineering, the biomedical engineering program at Western New England College recently hosted its first residential summer program for high school students. The objectives of 
this program were 1) to introduce students to the breadth and depth of the field of biomedical engineering, 2) to introduce students to career choices available to persons obtaining an undergraduate degree in biomedical engineering, and 3) to introduce students to the educational opportunities available within the biomedical engineering program at Western New England College.

\section{Participants}

Rising junior and senior high school students who selected biomedical engineering as a potential college major on either the SAT or PSAT were targeted as potential applicants for the program. Postcards advertising the program were sent to the approximately 6,500 students identified in this manner. In addition, a blast email of the postcard was sent to approximately 25,000 other rising junior and senior high school students who had expressed an interest in attending Western New England College and pursuing a pre-medical major.

To be considered for the program, applicants completed an application form and submitted a letter of recommendation from a teacher or guidance counselor as well as a high school transcript. Applicants were selected as potential participants based on high school grades and strength of the recommendation. Once they were selected for the program, participants were required to submit $\$ 1200$ tuition for the program which covered on-campus housing, food, and all program costs.

Twenty-seven students (13 female, 14 male) participated in the program. Of those, 10 were rising juniors and 17 were rising seniors. No information was collected on the race/ethnicity of the participants. The geographical distribution of the participants is shown in Figure 1(a). In comparison, the geographical distribution of current undergraduate biomedical engineering students at Western New England College is shown in Figure 1(b). Comparing Figures 1(a) and 1(b), it can be seen that the participants came from a wider geographical distribution than those students typically enrolling in the BME program at Western New England College, which generally attracts students from the New England and mid-Atlantic areas.

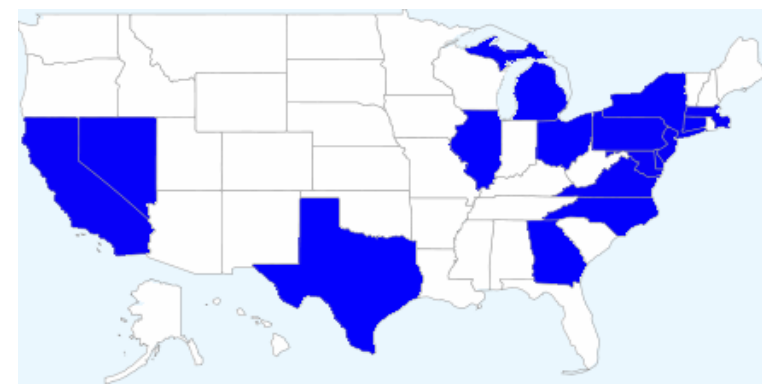

(a)

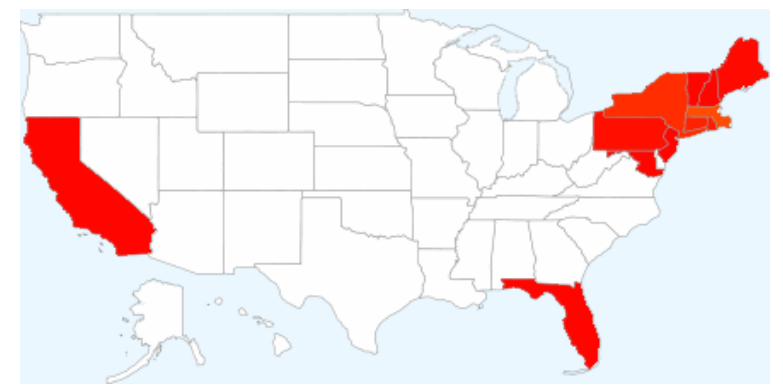

(b)

Figure 1: Geographical distribution (by state) of (a) participants of summer program and

(b) currently enrolled BME students 


\section{Description of program}

The one-week program ran from Sunday through Saturday, with lectures and laboratory experiences taking place during the day from Monday through Friday. Students were introduced to the field of biomedical engineering and typical career paths for BME students on Monday. Other lectures included training on laboratory safety related to biological, chemical, and physical hazards as well as an introduction to the laboratory experiences. Finally, a local surgeon that works with the BME faculty on design of breast surgery devices gave a lecture on his experiences in the medical field. Evening activities included a scavenger hunt, design of balloon powered vehicles, and the viewing of the movie "The Island" with a subsequent discussion of medical ethics and human cloning. The program culminated with an awards dinner and game night in the campus center. A brief schedule of the program is shown in Table 1.

\section{Laboratory experiences}

The overarching goal of the program was to introduce participants to the diverse field of biomedical engineering through the use of hands-on laboratory activities. The activities performed spanned the breadth of the biomedical engineering field.

\section{Biomaterials}

Through a series of laboratory activities several common materials science concepts were explored. Topics included polymeric crosslinking, hydrophobicity, hydrogels, biodegradation, drug delivery materials, viscosity, diffusion, polymerization, crystal structures, super-elasticity and shape memory alloys. The crosslinking experiment consisted of crosslinking a polyvinyl acetate solution with boric acid. The viscoelastic properties of the resulting "slime" were also demonstrated. The superabsorbent properties of sodium polyacrylate were explored for the hydrogel activity. The biodegradation and drug delivery exercises were adapted from the Biodegradable Materials module of the Materials World Modules developed at Northwestern University. ${ }^{6}$ The viscosity activity included observing the rheological properties of several fluids including the dilatant mixture of cornstarch and water. Diffusion was demonstrated by creating a brass alloy through heating a copper penny coated in zinc. Samples of NITINOL, a nickeltitanium alloy, were used to exhibit the shape memory effect and super-elasticity.

\section{Lab-on-a-Chip}

This module introduced the concept of microfluidic Lab-on-a-Chip technology to participants through a hands-on activity. Participants were first introduced to the basic concept of Lab-on-aChip through a PowerPoint presentation. Next, they designed a simple microfluidic mixer, which is a fundamental component of Lab-on-a-Chip devices, and then fabricated it using Shrinky Dinks plastic sheets. The designs were then tested by injecting colored dyes through the system using a vacuum pump to see how well the chip was able to mix the fluids.

\section{Bioinstrumentation}

This activity provided participants hands-on experience with two important pieces of bioinstrumentation: electrocardiograph (ECG) and medical imaging (ultrasound). They first learned the basic principles of operation for the instruments, and then made measurements on 
themselves and with phantoms. The module concluded with a discussion of different disease conditions that can be diagnosed with these medical devices.

Table 1: Schedule of Activities

\begin{tabular}{|c|c|c|c|c|c|c|}
\hline SUNDAY & MONDAY & TUESDAY & WEDNESDAY & THURSDAY & FRIDAY & SATURDAY \\
\hline & $\begin{array}{l}\text { Breakfast } \\
8-9 \text { AM }\end{array}$ & $\begin{array}{l}\text { Breakfast } \\
8-9 \text { AM }\end{array}$ & $\begin{array}{l}\text { Breakfast } \\
8-9 \text { AM }\end{array}$ & $\begin{array}{l}\text { Breakfast } \\
8-9 \text { AM }\end{array}$ & $\begin{array}{l}\text { Breakfast } \\
8-9 \text { AM }\end{array}$ & $\begin{array}{l}\text { Breakfast } \\
8-9 \text { AM }\end{array}$ \\
\hline & $\begin{array}{l}\text { Campus Tour } \\
9-10 \text { AM }\end{array}$ & $\begin{array}{l}\text { Intro to Lab } \\
\text { Experiments } \\
\text { 9-10 AM }\end{array}$ & \multirow{2}{*}{$\begin{array}{c}\text { BME Lab } \\
\text { Experiments } \\
9-11 \text { AM }\end{array}$} & \multirow{2}{*}{$\begin{array}{c}\text { BME Lab } \\
\text { Experiments } \\
\text { 9-11 AM }\end{array}$} & \multirow{3}{*}{$\begin{array}{c}\text { BME Lab } \\
\text { Experiments } \\
9-\text { noon }\end{array}$} & \multirow{2}{*}{$\begin{array}{l}\text { Move out of } \\
\text { residence hall } \\
\text { 9-11 AM }\end{array}$} \\
\hline & $\begin{array}{l}\text { Lab Safety } \\
10-11 \text { AM }\end{array}$ & \multirow{2}{*}{$\begin{array}{c}\text { BME Lab } \\
\text { Experiments } \\
10 \mathrm{AM} \text { - noon }\end{array}$} & & & & \\
\hline & $\begin{array}{l}\text { Intro to Design } \\
11 \mathrm{AM} \text { - noon }\end{array}$ & & $\begin{array}{l}\text { Tibial Fracture } \\
\text { Fixation Design } \\
11 \text { AM - noon }\end{array}$ & $\begin{array}{c}\text { Sports } \\
\text { Biomechanics } \\
11 \text { AM - noon }\end{array}$ & & \\
\hline & $\begin{array}{c}\text { Lunch } \\
\text { noon-1 PM }\end{array}$ & $\begin{array}{c}\text { Lunch } \\
\text { noon-1 PM }\end{array}$ & $\begin{array}{c}\text { Lunch } \\
\text { noon-1 PM }\end{array}$ & $\begin{array}{c}\text { Lunch } \\
\text { noon-1 PM }\end{array}$ & $\begin{array}{c}\text { Lunch } \\
\text { noon-1 PM }\end{array}$ & \\
\hline & $\begin{array}{c}\text { Intro to BME } \\
1-2 \mathrm{PM}\end{array}$ & \multirow{2}{*}{$\begin{array}{l}\text { BME Lab } \\
\text { Experiments } \\
1-3 \text { PM }\end{array}$} & \multirow{6}{*}{$\begin{array}{c}\text { Trip to } \\
\text { Amusement Park } \\
1-9 \text { PM }\end{array}$} & Sports & \multirow{3}{*}{$\begin{array}{c}\text { BME Lab } \\
\text { Experiments } \\
\text { 1-4 PM }\end{array}$} & \\
\hline & \multirow{2}{*}{$\begin{array}{l}\text { Microscopy/ } \\
\text { Forensics } \\
\text { 2-4 PM }\end{array}$} & & & $1-3$ PM & & \\
\hline & & $\begin{array}{c}\text { Admissions Info } \\
\text { 3-4 PM }\end{array}$ & & $\begin{array}{c}\text { Guest Lecturer } \\
3-4 \text { PM }\end{array}$ & & \\
\hline $\begin{array}{l}\text { Move into } \\
\text { residence hall } \\
\text { 4-6 PM }\end{array}$ & $\begin{array}{l}\text { Free Time } \\
\text { (Gym, Pool) } \\
\text { 4-6 PM }\end{array}$ & $\begin{array}{l}\text { Free Time } \\
\text { (Gym, Pool) } \\
\text { 4-6 PM }\end{array}$ & & $\begin{array}{l}\text { Free Time } \\
\text { (Gym, Pool) } \\
4-6 \text { PM }\end{array}$ & $\begin{array}{c}\text { Free Time } \\
\text { (Gym, Pool) } \\
\text { 4-6 PM }\end{array}$ & \\
\hline \multirow{2}{*}{$\begin{array}{c}\text { Welcome BBQ } \\
\text { and } \\
\text { Icebreakers } \\
\text { 6-9 PM }\end{array}$} & $\begin{array}{l}\text { Dinner } \\
\text { 6-7 PM }\end{array}$ & $\begin{array}{l}\text { Dinner } \\
\text { 6-7 PM }\end{array}$ & & $\begin{array}{l}\text { Dinner } \\
\text { 6-7 PM }\end{array}$ & \multirow{2}{*}{$\begin{array}{c}\text { Awards Dinner } \\
\text { and } \\
\text { Game Night } \\
\text { 6-9 PM }\end{array}$} & \\
\hline & $\begin{array}{c}\text { Scavenger Hunt } \\
7-9 \mathrm{PM}\end{array}$ & $\begin{array}{l}\text { Engineering } \\
\text { Design Projects } \\
\text { 7-9 PM }\end{array}$ & & $\begin{array}{l}\text { Medical Ethics: } \\
\text { Movie and } \\
\text { Discussion } \\
\text { 7-9 PM }\end{array}$ & & \\
\hline
\end{tabular}

\section{Microscopy}

This activity introduced participants to various techniques of microscopy, including optical microscopy, scanning electron microscopy (SEM), and atomic force microscopy (AFM).

Participants were presented with a murder mystery scenario in which various pieces of evidence 
had been collected. They then used the different microscopes to inspect the evidence at the micro- and nano-scale, and made conclusions as to which suspect committed the crime.

\section{Sports Biomechanics}

The sports biomechanics module included static and dynamic analysis of the human arm, the mechanics of a soccer kick, balance measured using a force plate and the mechanics of a football throw. The static and dynamic analysis of the human arm was explored using a human arm model with two force gages (Pasco). The mechanics of the soccer kick exercise consisted of observing the deformation of a soccer ball during foot strike using a high speed camera. Additionally, an accelerometer (Pasco) was affixed to the participant's lower leg. Velocity and acceleration measurements were made and a predicted travel length was calculated. A participant's center of mass on a force plate (Pasco) was used as a measurement of balance. The effects of vision and disturbance of the vestibular system were also explored in this module. The physics of a football throw were explored using an accelerometer embedded in a football using a wireless data transmission system (Pasco).

\section{Robotic Surgery}

In this module, participants were introduced to basic concepts involved with robotic surgery. First, the field of robotic surgery was described to students through a video-based presentation. The students then participated in a hands-on activity that allowed them to experience what a robotic surgical procedure would entail. A robotic arm kit (Robotic Arm Edge, OWI-535) was purchased and assembled prior to the program. The robotic arm was modified to include video capture devices (e.g., webcams), which were connected to monitors. The students were placed behind a curtain and instructed to use both the controller for the robotic arm and the video monitors to conduct a simulated surgical procedure. Their task was to use the robotic arm to replace an organ on a mock patient (e.g., a grape embedded in gelatin affixed to the chest of a children's doll measuring 24 inches tall by 12 inches wide). The students were timed during the operation to see who could complete the procedure the quickest.

\section{Engineering Design}

\section{Balloon-powered vehicle}

This activity was implemented as part of the evening program. Students were given a limited set of materials, such as balloons, straws, and lifesavers, each of which had been assigned fixed unit costs. The goal was to design a vehicle using a balloon as the power source that traveled the farthest distance while also maximizing the cost efficiency. A competition was held to determine the overall winner, with prizes awarded to the top three overall designs. This activity exposes students to the design principles that engineers use while also reinforcing physical concepts such as force and system stability.

\section{Tibial fracture fixation}

This activity introduced the concepts of engineering design, biomaterials, biomechanics and physiology. Prior to the initiation of this activity a short lecture was provided on the engineering design process. A worksheet was also provided guiding students through the design process. Students were then split into design teams of 3-4 members. Foam tibia bones (Sawbones) were then fractured using a mechanical testing device (Instron). The task given was to design a tibial 
fracture fixation device with a limited number of materials. Design prototypes were tested for weight and ability to withstand the maximum force at fracture when deflected at $150 \mathrm{~mm} / \mathrm{min}$ using the Instron machine. At the end of the program, prizes were given to the groups a) whose fixation device withstood the maximum force, b) whose device had the lightest weight design meeting the minimum criteria and c) who best demonstrated the design process.

\section{Cell and tissue engineering}

This activity was modeled on the cell-based biocompatibility module developed by educators at Bucknell University ${ }^{7}$ and introduced participants to the basics of mammalian cell culture. The students were first instructed on the fundamentals of aseptic technique. Next, they evaluated how different materials that may be used in vivo affect the viability of cells surrounding the material. Each participant received a T-25 flask of bovine aortic endothelial cells. They changed the media in the flask, and then added a piece of sterile metal or polymer to the culture. The flask was inspected after either 24 or 48 hours to determine the viability of cells near the added material to determine the biocompatibility of the material.

\section{Neural engineering}

This activity provided an understanding of how the brain is able to control parts of the body through the neural motor pathways. Participants were introduced to the anatomy and physiology of the brain including the waves typically measured via electroencephalography. Participants then experimented with a neural impulse actuator (nia, OCZ Technology, Inc., Sunnyvale, CA), a computer game controller that measures electrical potentials (electroencephalogram, electrooculogram, and electromyogram) from the forehead of the user to control switching events and joystick movements. Participants first used this interface to measure reaction time then played a computer game against the computer. The participants having the top reaction times were awarded prizes.

\section{Physiological response to acceleration}

The physiological response to acceleration was evaluated by measuring heart rate of participants while riding various rides, most notably a roller coaster with a $221 \mathrm{ft}$. drop, at a local amusement park. A Pasco Passport system equipped with a 3-axis accelerometer, altimeter and heart rate monitor was used to record data while on the various rides. After returning from the amusement park the data were downloaded and analyzed noting the correlation of heart rate, altitude and acceleration.

\section{Assessment of program}

The success of the program was evaluated using pre- and post-surveys (included in the Appendix) which include both quantitative and qualitative assessment of the program. This program assessment was approved by the Institutional Review Board at the host institution. At the orientation on the first night of the program, each participant received both the pre- and postprogram surveys. Pre- and post-program surveys for a given participant had the same randomly generated 6-digit number to maintain the confidentiality of the respondent. The survey responses were typewritten by administrative staff prior to analysis by the investigators to remove recognition of handwriting as an identifier of responses. Twenty-seven participants completed 
the pre-program survey while twenty-five completed the post-program survey. The data analysis includes data only for those participants completing both surveys.

The impact of the lab experiences was assessed quantitatively using two 5-choice Likert questions: "What is your confidence level in performing engineering calculations?" and "What is your confidence level in performing laboratory work in biomedical engineering?" with a score of zero corresponding to no confidence and a score of four corresponding to very confident. The familiarity of participants with the BME program at the host institution was also measured with a 5-choice Likert question: "How familiar are you with the Biomedical Engineering program at Western New England College?" with a zero corresponding to no familiarity and a four corresponding to quite familiar. These quantitative Likert questions were analyzed using a onetailed, paired t-test with a significance level of 0.05 since it was assumed that the participants' scores would increase as a result of the program.

The mean responses to the questions related to the impact of the lab experiences are shown in Figures 2 and 3. There is a significant increase in participant confidence in performing engineering calculations $(\mathrm{p}=0.026)$ and confidence in performing lab work in biomedical engineering $(\mathrm{p}=0.0004)$.

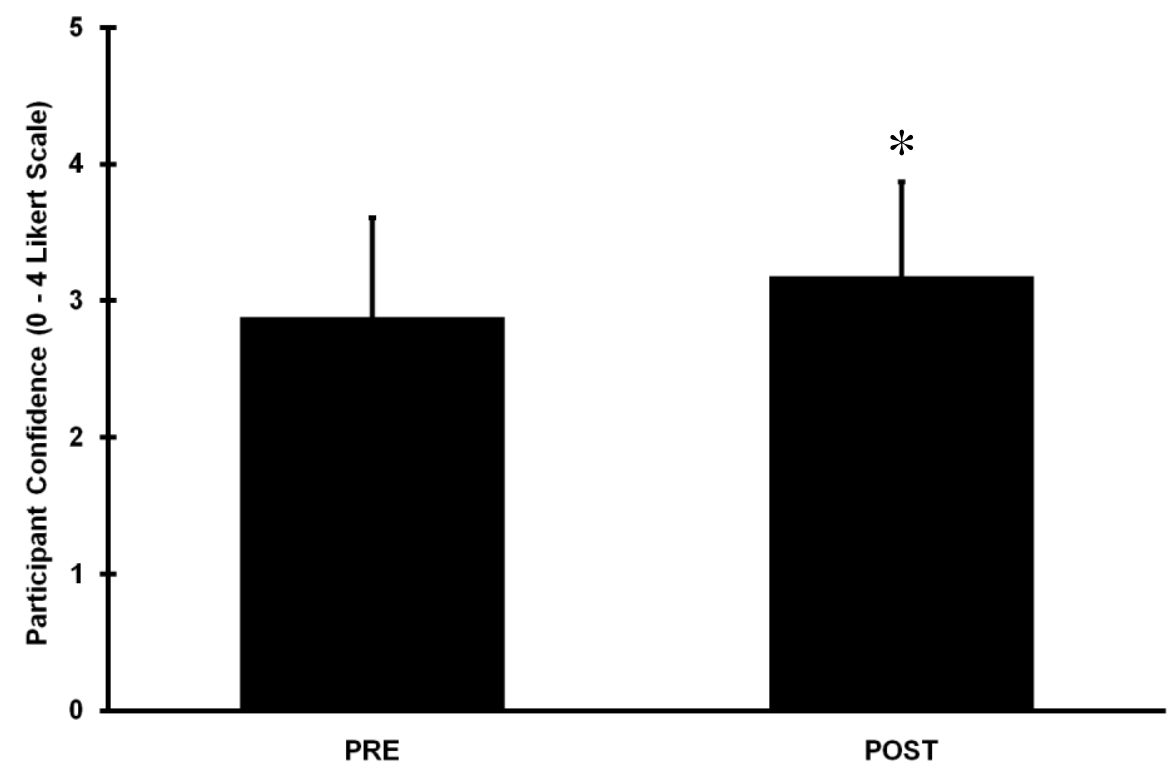

Figure 2: Participant confidence (Likert scale 0-4) in performing engineering calculations. Results are shown as mean + standard deviation. $* p=0.026$ 


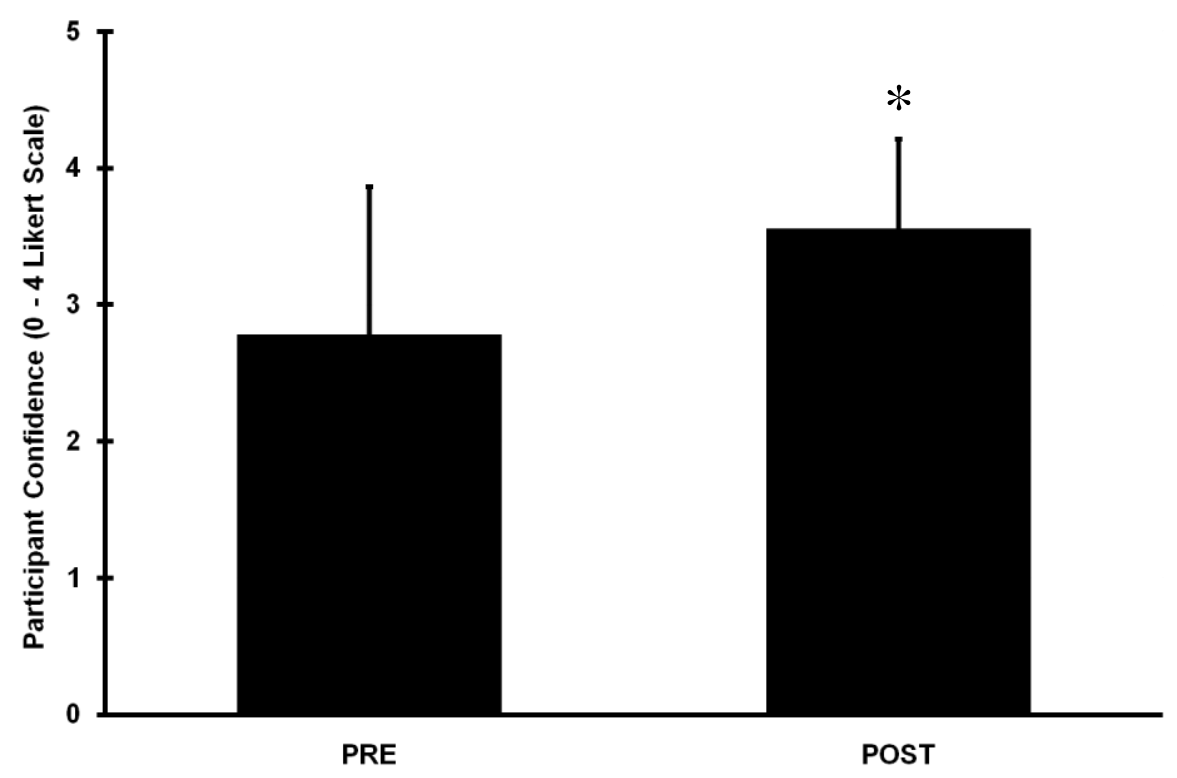

Figure 3: Participant confidence (Likert scale 0-4) in performing laboratory experiments in biomedical engineering. Results are shown as mean + standard deviation. ${ }^{*} \mathrm{p}=0.0004$

Figure 4 shows the participants' familiarity with the biomedical engineering program at Western New England College before and after the program. It is clear that the objective to introduce the high school students to the educational opportunities available within the biomedical engineering program at Western New England College was met $\left(\mathrm{p}=1 \times 10^{-10}\right)$. It is assumed that the participants' impressions of the biomedical engineering program at Western New England College were favorable as 9 listed the institution as a college to which they plan to apply on the pre-program survey while 12 listed it on the post-program survey.

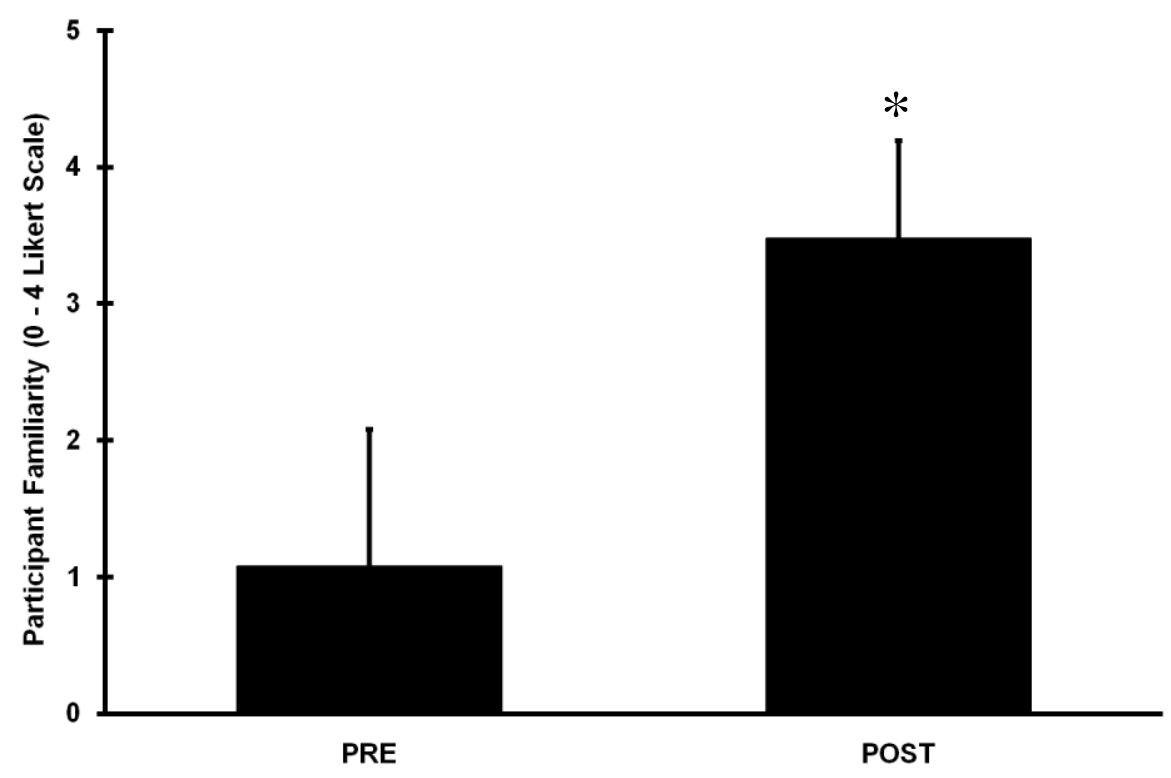

Figure 4: Participant familiarity (Likert scale $0-4$ ) with biomedical engineering program at Western New England College. Results are shown as mean + standard deviation. $* \mathrm{p}=1 \times 10^{-10}$ 
The open-ended questions on the surveys also provide qualitative feedback on the success of the program. Many of the participants were familiar with subspecialties within the field of biomedical engineering listing items such as clinical engineering, biomechanics, surgical devices, tissue engineering, and biomechanics on the pre-program survey when asked to list subspecialties in BME. No student, however, listed bioinstrumentation on the pre-program survey while four students listed it as a BME sub-specialty on the post-program survey. Thus, the program was successful in introducing participants to new areas within the biomedical engineering field to which they were previously unaware.

The program was also successful in demonstrating the breadth of career choices available to graduates of biomedical engineering programs. As an example, on the pre-program survey, twelve participants listed research as a job performed by biomedical engineers while one student listed lawyer as a career choice on the pre-program survey. In contrast, on the post-program survey, fourteen participants listed research while five listed lawyer or law school or patent law. Again, these responses demonstrate that the program was successful in exposing participants to the broad range of career choices available for biomedical engineers.

The overall success of the program can be assessed by the questions related to what the participants liked and did not like about the program. For the most part, participants were pleased with the program as demonstrated by the following comments on the post-program survey in response to the question: "What did you like most about this summer program?"

I liked the hands on lab experience and experiments. I liked the helpful staff and creative activities.

Learning something new in every lab and making friendships all the while. The whole experience was pretty amazing and the professors were pretty awesome.

Working with other students, having access to the professors and state of the art machinery

Helped me to explore all types of biomedical engineering

The different types of labs, the people, the professors, the whole learning experience

I liked the amount of time we spent in the lab. I really enjoyed all the experience we got with many different fields of BME

The introductory instruction to biomedical engineering. It provided for me an excellent taste of the study

It was nice to see that I enjoyed my future profession

It helped me discover more about biomedical engineering

When asked "What did you not like about this summer program?" many of the participants listed items related to the logistics of the program such as scheduling, lack of a curfew, and the need to be accompanied by a staff member at all times while on campus. The forensics/microscopy experiments were also singled out for improvement. Comments included 
I didn't particularly like how we had to walk w/ an adult everywhere we went. At previous universities I could walk anywhere on campus $w /$ a buddy. The afternoon lab on the first day seemed a little hectic and wasn't really that fun.

More freedoms, break up the lab time

Getting up early

Too much time to eat, scavenger hunt, need an escort EVERYWHERE

I didn't like the restrictions placed on us and how we did a lot of different labs in rapid succession without really focusing on any particular thing

Chunks of activities were too large (shorter classes \& more/shorter breaks)

Waking up so early, but it wasn't that bad

\section{Forensics}

The logistics of the program with respect to the scheduling of activities and the forensics/ microscopy experiment will be re-evaluated prior to the next offering of the program, tentatively scheduled for summer 2011.

\section{Discussion}

We have described a unique residential summer program that exposes high school students to the breadth of possibilities regarding sub-specialties and career opportunities available to biomedical engineers. Although similar in aim and length to the program at the Milwaukee School of Engineering, our program contained a different set of experimental modules, as much of their program focuses on biosignals and the design of instrumentation to measure them. ${ }^{1}$ The quantitative assessment performed demonstrates that participants have increased confidence in their ability to perform experiments and calculations related to the biomedical engineering field as a result of the program. The increase in confidence level for performing engineering calculations is intriguing as no calculations were required for any of the laboratory modules. This may reflect an overall increase in confidence related to a better understanding of the biomedical engineering field. The increase in confidence in performing laboratory experiments is likely due to their performance of multiple hands-on experiments over the span of the program. In addition, the participants increased their knowledge of the educational opportunities available for them in the biomedical engineering program at Western New England College. It is likely that many of the participants were unaware of the institution itself as well as the biomedical engineering program prior to receiving the promotional literature for the program. The participants also had the opportunity to work in the labs alongside BME faculty and current students, thus familiarizing themselves with the environment within the BME program. The qualitative assessment suggests that participants did broaden their knowledge with respect to the sub-specialties and career opportunities in biomedical engineering.

Participants were pleased with the overall experience provided by the program, but offered feedback on program scheduling and laboratory experiences that can be improved. Planning is 
underway for the next offering of the program that will consider the feedback provided. Because a major objective of the program is to demonstrate the breadth of the biomedical engineering field, participants will still perform experiments on a broad range of topics from lab-on-a-chip to biomaterials to bioinstrumentation and thus a wide variety of topics will be covered in a short period of time. The forensics experiment will be revamped and expanded to provide an introduction to microscopy (light, SEM, AFM) followed by self-paced experimentation on "evidence" to solve the forensic mystery. Participants will also be given more time to develop and test their fracture fixation devices. The single guest speaker will be replaced with a panel having a practicing engineer, attorney, and physician who can elaborate on the variety of career paths available to biomedical engineering graduates.

A primary impetus for the offering of the summer program at Western New England College was to increase the undergraduate enrollment in biomedical engineering. The goal was to recruit nationwide for participants in the program, rather than focusing on those areas already targeted by the campus admissions office in an effort to expose more high school students to the BME program at Western New England College. The summer program did draw participants from a broader geographical area than that of the current students enrolled in the BME program. Admissions data will be tracked to determine if the summer program, through participation or receipt of advertising, leads to a broadening of the geographical distribution and increase in enrollment of students within the BME program at Western New England College.

The National Science Foundation recognizes the role of informal science education such as that provided by summer programs and continues to fund these programs to introduce middle and high school students to opportunities in STEM-related fields. ${ }^{8,9}$ Thus, the educational experiences developed for this program are relevant to the wider biomedical engineering educational community. These modules and those developed for other bioengineering summer programs can be disseminated throughout the biomedical engineering educational community for use in outreach activities to introduce the next generation of middle and high school students to the field of biomedical engineering, broadening the impact beyond the benefits derived for the host institution.

\section{References}

[1] Milwaukee School of Engineering. "Focus on the Possibilities: Biomedical Engineering." Internet: http://www.msoe.edu/high_school_students/summer_programs/biomedical_engineering.shtml, [Mar 11, 2011].

[2] University of Washington. "K-12 Resource Guide: Bioengineering Summer Camp." Internet: www.outreach.washington.edu/k12guide/resourcepage.asp?ProjID=400, [Dec. 30, 2010].

[3] Wichita State University. "Summer Bioengineering Camp Challenges High School Students - Wichita State News.” Internet: www.wichita.edu/thisis/wsunews/news/?nid=323, Nov. 19, 2008 [Dec. 30, 2010].

[4] Wichita State University. "Engineering Summer Camps." Internet: webs.wichita.edu/?u=engineeringcamps\&p=/index09, Jul. 12, 2009 [Dec. 30, 2010]. 
[5] University of Illinois at Urbana-Champaign. "Bioengineering \& Chemical Engineering." Internet: wiki.engr.illinois.edu/pages/viewpage.action?pageId=34177540, [Dec. 30, 2010].

[6] M. Hsu, R. DeWald, and K. Turner. "The materials world modules program: incorporating technology in pre-college education," in Materials Research Society Symposium Proceedings, v 684 (Impacting Society through Materials Science and Engineering Education), 2001, pp. 61-72.

[7] D. M. Ebenstein, E. A. Kennedy, J. V. Tranquillo, and D. P. Cavanagh. "A cell culture-based biocompatibility module for biomedical engineers," in Proceedings of the Biomedical Engineering Society Annual Meeting, 2009.

[8] George Mason University. "ITEST: Game Design through Mentoring and Collaboration," Internet: http://itest.gmu.edu/, [Mar 11, 2011].

[9] National Science Foundation. "News - Can a Robot Get High School Students Interested in Studying Science and Engineering in College?" Internet:

http://www.nsf.gov/news/news images.jsp?cntn_id=110002\&org=NSF, Dec 10, 2010 [Mar 11, 2011]. 


\section{Appendix}

\section{Pre-program Survey \\ BME Summer Program for Elite High School Students}

We are performing research to evaluate the usefulness of the BME Summer Program for Elite High School Students. To do this we will survey you before and after the program. Please complete the attached survey and place it in the envelope posted in the lobby. You may choose not to answer any or all questions. You may choose to not participate or withdraw from this study at any time for any reason. Withdrawing from the study will not affect your participation in the program.

If you have any questions, please contact Dr. Cezeaux

What are your favorite classes in school? Check all that apply.

English/Literature
Mathematics
Chemistry
_ Physics
Biology
History
Foreign Language
Other

What do you plan to do when you graduate from college? Place checkmark next to your top choice.

Find job in medical device industry

Find job in pharmaceutical industry

Find job in biomedical research

Graduate study

Medical school

Other

What is biomedical engineering?

What are some sub-specialties in biomedical engineering?

What kind of jobs do biomedical engineers do?

What is your confidence level in performing engineering calculations?

$\begin{array}{cllll}\text { Very confident } & & & \text { No confidence } \\ 4 & 3 & 2 & 1 & 0\end{array}$

What is your confidence level in performing laboratory work in biomedical engineering?

Very confident

4

3
2

1
No confidence

0 
How familiar are you with the Biomedical Engineering program at Western New England College?

Very familiar

4

3

2

Not familiar

0

List the colleges/universities to which you plan to apply.

What do you expect to get out of this summer program?

0
$\mathbb{0}$
$\mathbb{D}$
$N$
$N$
0
0
0
जे 


\section{Post-program Survey BME Summer Program for Elite High School Students}

We are performing research to evaluate the usefulness of the BME Summer Program for Elite High School Students. To do this we will survey you before and after the program. Please complete the attached survey and place it in the envelope posted in the lobby. You may choose not to answer any or all questions. You may choose to not participate or withdraw from this study at any time for any reason. Withdrawing from the study will not affect your participation in the program.

What are your favorite classes in school? Check all that apply.

English/Literature
— Mathematics
_ Chemistry
— Physics
— Biology
- History
_ Foreign Language
_ Other

What do you plan to do when you graduate from college? Place checkmark next to your top choice. Find job in medical device industry Find job in pharmaceutical industry

_ Find job in biomedical research Graduate study Medical school Other

What is biomedical engineering?

What are some sub-specialties in biomedical engineering?

What kind of jobs do biomedical engineers do?

What is your confidence level in performing engineering calculations?

Very confident

4 3 2

1

No confidence 0

What is your confidence level in performing laboratory work in biomedical engineering?

Very confident

4
3
2
No confidence

0 
How familiar are you with the Biomedical Engineering program at Western New England College?

Very familiar

4

3

2

Not familiar

0

List the colleges/universities to which you plan to apply.

What did you like best about this summer program?

What did you not like about this summer program?

If you have any other comments about the BME Summer Program or Western New England College, please include them below. 